\title{
POLÍTICAS PÚBLICAS DE SEGURANÇA E A QUESTÃ̃ POLICIAL
}

\author{
Cláudio C. Beato Filho \\ Professor do Departamento de Sociologia e Antropologia da UFMG
}

$\mathrm{E}$ ste artigo discutirá, em sua primeira seção, a criminalidade violenta como um problema social no Brasil, através da demonstração e localização de sua dimensão no Estado de Minas Gerais, bem como algumas estimativas do custo econômico que ele acarreta. A segunda seção tratará das condições em que este problema social torna-se um problema público, o que significa examinar as condições e deficiências de ordem cognitiva na formulação de políticas públicas nesta área. A terceira parte será uma discussão acerca do sistema de justiça criminal, em especial sobre a polícia no Brasil. A quarta será dedicada à discussão acerca das soluções encontradas em outros países para o problema da segurança pública. Finalmente, serão discutidas algumas questões referentes às políticas de segurança pública no Brasil.

\section{A VIOLÊNCIA COMO PROBLEMA SOCIAL}

Poucos problemas sociais mobilizam tanto a opinião pública como a criminalidade e a violência. Não é para menos. Este é um daqueles problemas que afeta toda a população, independentemente de classe, raça, credo religioso, sexo ou estado civil. São conseqüências que se refletem tanto no imaginário cotidiano das pessoas como nas cifras extraordinárias representadas pelos custos diretos da criminalidade violenta. Receosas de serem vítimas de violência, elas adotam precauções e comportamentos defensivos na forma de seguros, sistemas de segurança eletrônicos, cães de guarda, segurança privada, grades e muros altos, alarmes, etc. Já se disse que o presídio tornou-se modelo de qualidade resi- dencial no Brasil. Nos Estados Unidos, de acordo com o National Crime Victimization Survey, apenas durante o ano de 1992, calcula-se que vítimas de crimes perderam 17,6 bilhões de dólares em custos diretos referentes a furtos, arrombamentos, assaltos, estupros e despesas médicas imediatas. No Brasil, estimam-se os gastos anuais com segurança pública no Município do Rio de Janeiro em cerca de 2 bilhões e meio, o equivalente a 5\% do PIB municipal (Piquet Carneiros et alii, 1998). Neste cálculo, são computados gastos com atendimento médico, anos perdidos pela morte ou incapacidade prematura, gastos com o sistema de segurança e justiça, além de transferências sociais na forma de seguros. É uma estimativa conservadora, pois não leva em conta os gastos com segurança privada, bem como os efeitos da violência sobre os investimentos privados. Se fossem utilizados os estimadores hedônicos para avaliar o peso da segurança nos valores do uso da propriedade, tais como a residência ou o valor do aluguel destas residências conforme sua localização geográfica, estes custos aumentariam ainda mais. ${ }^{1}$ Em Minas Gerais, durante o ano de 1995, o governo do estado gastou $\mathrm{R} \$ 940$ milhões com seu sistema de segurança, o que equivale a $10 \%$ do orçamento total realizado durante este ano (Gonçalves, 1996). ${ }^{2}$ São cifras suficientes para amenizarmos outros problemas em setores igualmente estratégicos, tais como saúde, educação ou habitação.

Embora o temor da violência seja universalmente distribuído em toda a sociedade, as vítimas de fato estão concentradas apenas em alguns setores. Em Minas Gerais, 
segundo dados do Ministério da Saúde, quase 90\% das vítimas de homicídios são do sexo masculino. Metade concentra-se nas faixas mais jovens da população (entre 15 e 30 anos). Nos Estados Unidos, quem tem renda familiar anual inferior a $\$ 15.000$ tem três vezes mais chances de ser estuprado ou sofrer algum tipo de violência sexual do que as pessoas com renda superior. Tem também duas vezes mais chances de ser vítima de roubo, e uma vez e meia de ser vítima de assaltos com violência. Não é difícil imaginar que, no Brasil, esta distribuição perversa e desigual dos custos da violência poderia ser ainda mais acentuada. Qualquer indicador que tomemos para traçar o perfil das vítimas de crimes certamente apontará para o fato de que são as classes menos favorecidas as maiores vítimas.

Outro problema a ser levado em consideração é que a violência e a criminalidade concentram-se nos grandes centros urbanos. O crescimento da criminalidade violenta no Estado de Minas Gerais, nos últimos 12 anos, como mostra o Gráfico 1, foi muito mais acentuado nas cidades com mais de 100 mil habitantes. Cidades menores têm menores taxas, que são mantidas a um ritmo constante ao longo desses anos. Quanto maior a faixa de população, maiores as taxas, sendo que nas faixas acima de $100 \mathrm{mil}$ habitantes, o ritmo de crescimento é cada vez mais vertiginoso.

Um exame do comportamento dessas curvas de forma desagregada irá mostrar outras características na ascensão destas taxas. Esse crescimento deveu-se, principalmente, ao aumento do número de crimes violentos contra o patrimônio, que a cada ano apropria-se de uma parcela cada vez maior do total de crimes violentos. É notável o crescimento do roubo à mão armada que, durante o período, apresentou um aumento significativo: de uma taxa de 14 por 100 mil habitantes no ano de 1986, assistimos a um aumento de 5,7 vezes, para chegarmos ao ano de 1997 com uma taxa de 80 por 100 mil. Isto significou um incremento anual de 4,2 crimes para cada grupo de 100 mil habitantes. Apenas nos dois últimos anos da série, a taxa deste tipo de delito praticamente dobrou, partindo de 40 por 100 mil em 1996 para atingir 80 em 1997. Sem dúvida nenhuma, este é o tipo de delito que mais contribuiu para o aumento da criminalidade violenta em Minas Gerais, o que indica uma mudança muito clara no padrão de criminalidade no Estado.

Qual tem sido a resposta governamental a este tipo de situação que, acreditamos, não é tão diferente em outros estados brasileiros?

\section{A VIOLÊNCIA COMO UM PROBLEMA PÚBLICO}

Crime, acidentes de trânsito ou delinqüência de menores são problemas sociais, mas como eles se tornam problemas públicos? Isto é algo que envolve uma atuação mais moralmente empreendedora por parte do Estado, além do envolvimento de diversas instituições às quais cabe a responsabilidade de apresentar múltiplas possibilidades de resolução. Assim, responder à questão do crime como um problema público remete-nos à discussão acerca das dimensões culturais e estruturais envolvidas. Isto implica necessariamente atribuirmos responsabilidade a quem cabe resolvê-lo: significa decidir quem é seu "proprietário". Quem exerce autoridade no encaminhamento de soluções ? Governantes, legisladores, policiais, sociólogos, o Judiciário? São questões a respeito do consenso existente sobre o crime como um problema público e sobre as causas e "terapêuticas" adequadas, e a existência de diferentes instituições e pessoas encarregadas da resolução do problema (Gusfield, 1981). Como o problema deve ser atacado? Preventivamente ou em seus sintomas? Quais as variáveis relevantes a serem arroladas para a resolução do problema? Quais, enfim, os fatores determinantes tomados em consideração? Temos aqui uma série de alternativas que buscam "resolver" o problema do crime. $\mathrm{O}$ aspecto moral, aliado à identificação de causas do fenômeno, entretanto, é que torna a erradicação do problema algo desejável: "sem uma crença cognitiva na possibilidade de mudança e um julgamento moral de seu caráter, um fenômeno não está em questão, não é um problema" (Gusfield, 1981:10).

É um aspecto dramático do problema do crime no Brasil que ele venha a ser objeto da atenção de nossos governantes somente quando ultrapassar os limites estruturais aos quais está tradicionalmente confinado. Quando estende-se à classe média e à zona sul, imediatamente soam os alarmes da mídia e a indignação das elites. Nesse momento, as pessoas põem-se a especular a respeito das causas da criminalidade a fim de combatê-la. Uma das teses, bastante recorrente, aliás, é a de como o crime estaria "evidentemente" associado à pobreza e à miséria, à marginalidade dos centros urbanos e a processos migratórios. ${ }^{3}$ Este é o argumento da contaminação dos valores das pessoas pela necessidade mais premente da sobrevivência a qualquer custo. Felson (1994) refere-se a esta perspectiva como a "falácia da pestilência": “...as coisas ruins provêm de outras coisas ruins. O crime é uma má coisa, portanto, ele 
deve emergir de outras maldades tais como o desemprego, pobreza, crueldade e assim por diante. Além disso, a prosperidade deveria conduzir-nos a taxas mais baixas de crime."

Após identificada a suposta causa do crime, este seria rapidamente erradicado desde que houvesse vontade política. Assim, o messianismo que marca outros setores da vida brasileira não poderia estar ausente da formulação de políticas de segurança pública. Da mesma forma que a inflação deve ser abatida com um tiro apenas, o analfabetismo com uns trocados a mais nos bolsos dos professores, a distribuição de renda com alguns golpes de caneta, ou o problema da saúde com um pouco mais de recursos, a criminalidade seria combatida mediate políticas de combate à pobreza, miséria e de geração de empregos.

Trata-se de um argumento moralmente ambíguo, pois procura combater a pobreza, a desigualdade e a miséria não pela sua própria existência (que em si mesma é injustificável), mas associando-a a uma espécie de ameaça à tranquiilidade das classes média e alta. Além disso, ele deveria prestar conta de alguns dados desconcertantes, tais como o fato de criminalidade e violência não estarem associadas ao crescimento do desemprego no Brasil durante a década de 80 (Coelho, 1988). Ou então, que o crescimento vertiginoso da criminalidade nos anos 60, nos Estados Unidos, coincide justamente com um período de investimentos maçicos em políticas assistenciais pelo governo americano (Wilson, 1983). Ou ainda, o resultado de uma pesquisa sobre população prisional no Estado de São Paulo mostrando que mais da metade dos prisioneiros trabalhava à época de sua prisão, sendo em sua maioria nascidos e criados em São Paulo (Brant, 1986).

\section{Deficiências Cognitivas na Formulação do Crime como Problema Público}

Certamente, não é surpresa para muitos que o debate acerca das causas do crime não é consensual na comunidade acadêmica. Não obstante, a formulação de políticas públicas pode perfeitamente prescindir da identificação dessas "causas" (Wilson, 1983). Políticas devem pautarse por metas claras e definidas a serem alcançadas através de medidas confiáveis para a avaliação desses objetivos e pelos meios disponíveis para sua realização de forma democrática. A condição desejável a ser perseguida pode consistir na redução de alguns tipos de crimes específicos a um custo razoável para sua implementação. É pos- sível pensarmos numa redução não de todos os tipos de crime mas, por exemplo, em uma redução das taxas de roubo de veículos à mão armada, ou de assaltos a caminhões de carga. Quem sabe pensarmos num decréscimo significativo das escandalosas taxas de violência no trânsito em Minas Gerais. ${ }^{5}$ Portanto, uma análise de políticas públicas em segurança envolveria necessariamente a formulação de componentes informacionais a respeito dos programas a serem implementados, bem como métodos analíticos de monitoramento e avaliação de sua performance (Dunn, 1981). A formulação de problemas, alternativas, ações e resultados é essencialmente uma questão de natureza teórica, ao passo que a avaliação, monitoramento, recomendações e estruturações são questões de ordem técnica, envolvendo a utilização de modelos de custo/benefício, de efetividade, eficiência e de eqüidade.

No caso do sistema de Justiça Criminal no Brasil, ainda não dispomos de um sistema de informações de criminalidade em âmbito nacional, de tal forma que possamos avaliar a implementação de programas e estratégias de controle da criminalidade. Em Minas Gerais, apenas recentemente iniciamos a organização de um sistema de informações sobre a criminalidade violenta nos municípios do Estado. São dados relativos a um período de 12 anos que nos permitem avaliar mais adequadamente o impacto de políticas nos âmbitos federal, estadual e local sobre as taxas de criminalidade. Estas informações são um passo inicial que podem contribuir para a reestruturação desses programas e políticas, bem como fornecer subsídios para reformulações na legislação, além da avaliação das conseqüências do crime sobre a economia, ou o impacto das variáveis socioeconômicas sobre a criminalidade.

Por ora, vamos nos deter em alguns problemas de natureza conceitual, dadas as implicações que podem ter nas formulações de políticas públicas de segurança. Uma das dificuldades para identificar as variáveis responsáveis pelo crime está no fato de estarmos tratando de um conceito a violência - que envolve comportamentos diferentes, bem como uma diversidade grande de eventos. Quando falamos do "crime", estamos falando de fenômenos muito distintos: "roubar uma revista em quadrinhos, esmurrar um colega, sonegar impostos, assassinar a esposa, roubar um banco, corromper políticos, seqüestrar aviões - esses e inumeráveis outros atos são crimes" (Wilson e Herrenstein, 1985:21). A heterogeneidade de eventos e fenômenos encobertos sob o conceito de violência acarreta dificuldades para a formulação de políticas públicas que são de 
ordem cognitiva, pois significa identificar fatores de risco distintos a cada situação. Somos levados a buscar soluções para problemas tão distintos como o crime das ruas, delinquiência de menores, tráfico de drogas, roubos à mão armada, crime organizado, estupros, crimes que envolvem organizações empresariais, etc. $\mathrm{O}$ caso do crime organizado, que está cada vez mais presente nas grandes capitais, ilustra os equívocos decorrentes desta conceituação ampla. O crime organizado representa um padrão de criminalidade que se distingue da comum, por "estar organizada como associações empresariais estáveis com objetivos de cometer atos ilícitos e lucrativos, que envolvem a participação, por ação ou omissão, de agentes públicos" (Caldeira, 1998). Trata-se, portanto, de delitos cujas características específicas envolvem uma relação estreita com órgãos governamentais e com o aparelho do Estado. Esta simbiose nos conduz necessariamente ao controle que temos sobre as organizações que compõem o sistema de Justiça Criminal, tais como a polícia, a Justiça, o Ministério Público, as penitenciárias, etc.

O problema é complexo e exige um diagnóstico adequado. A primeira hipótese sob exame é que este tipo de crime acarreta o crescimento de algumas modalidades de crime, tais como furto e roubo de veículo e tráfico de drogas. É justamente este tipo de criminalidade que tem crescido nas grandes cidades, tal como ocorre em Minas Gerais. Esta tendência de evolução dos crimes violentos contra a propriedade é expressiva da mudança nos padrões de criminalidade no Estado. Conforme veremos a seguir, a participação percentual dos crimes contra a propriedade é crescente. A cada ano, este tipo de delito abocanha uma parcela maior do total de crimes violentos. No início do período, em 1986, os delitos contra a propriedade contabilizavam cerca de 41,7\% do total de crimes violentos. Em 1997, passaram a contribuir com $71,7 \%$ do total. Uma das questões a ser enfrentada refere-se a uma legislação penal adequada ao combate deste tipo de crime. No caso brasileiro, não há uma definição normativa sobre o tema, embora tenhamos leis específicas, tais como a legislação sobre crimes hediondos ou a lei que disciplina a lavagem de dinheiro (Caldeira, 1998). Esta é um dos temas em pauta no anteprojeto do Código Penal, mas já se podem antever as imensas dificuldades que os próprios juízes e legisladores colocarão sobre o tema (Grinover apud Caldeira, 1998).

\section{GRÁFICO 1}

Taxa de Crimes Violentos, por Tamanho da Cidade Estado de Minas Gerais - 1986-97

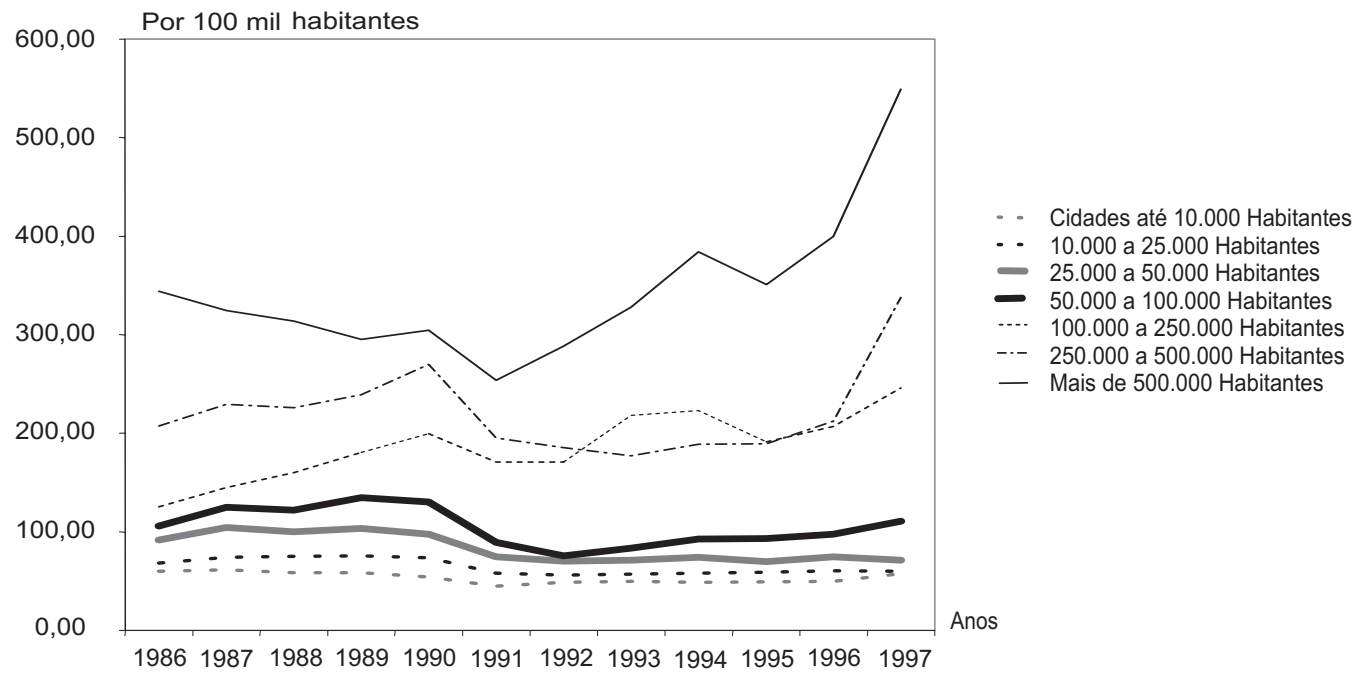

Fonte: Polícia Militar de Minas Gerais. 


\section{GRÁFICO 2}

Participação dos Crimes Violentos, por Tipo

Estado de Minas Gerais - 1986-97

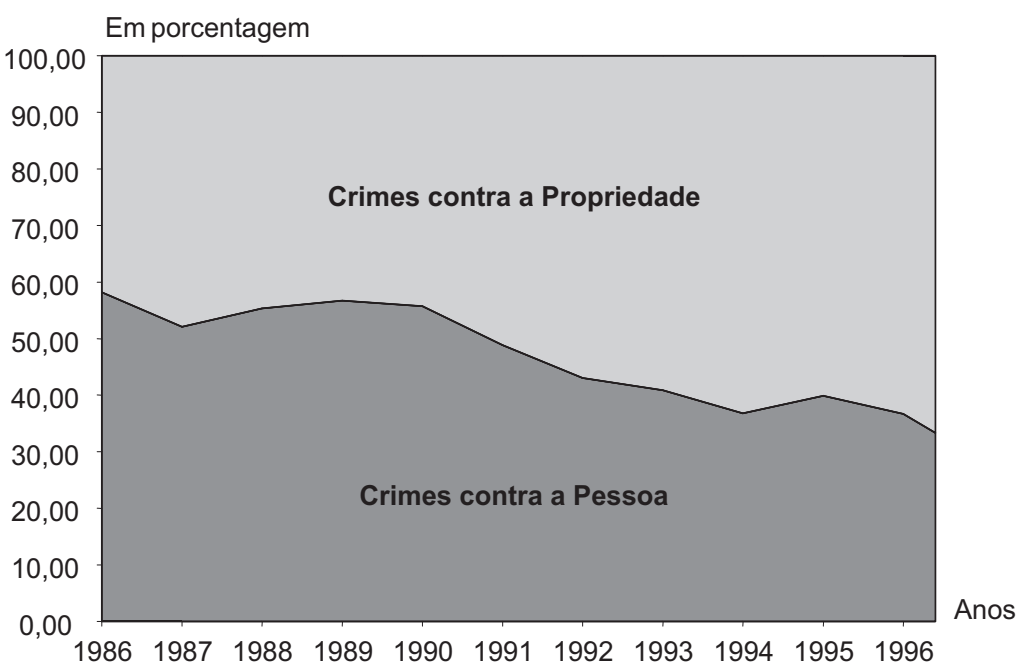

Fonte: Polícia Militar de Minas Gerais.

\section{O SISTEMA DE JUSTIÇA CRIMINAL: O PROBLEMA DA ORGANIZAÇÃO POLICIAL}

Não dispomos de análises mais detalhadas sobre a integração funcional das diversas organizações do sistema de justiça criminal. O que parece ser uma constante é uma certa "desconfiança" quanto à integração das várias organizações do sistema de Justiça Criminal, sem que saibamos exatamente a causa desses conflitos de jurisdições. Alguns diagnósticos preliminares acerca do nosso sistema de Justiça Criminal destacam o "caráter frouxamente articulado" da relação entre as organizações que compõem o sistema (Paixão, 1993; Coelho, 1986) que termina por operar uma disjunção entre o aparelho policial e a administração da polícia (Coelho, 1986). Na ponta inicial, as polícias operam de forma igualmente desarticulada (Paixão, 1993), o que ensejou as inúmeras propostas de integração entre elas, seja suprimindo simplesmente a força militar, seja unificando seus comandos.

O tema "polícia" é ilustrativo dos percalços e vicissitudes que a segurança pública enfrenta na formulação de políticas nessa área no Brasil. A polícia tem preenchido largos espaços na mídia, especialmente no decorrer do ano que passou. Aos episódios de Carandiru e Vigário Geral vieram somar-se os da Favela Naval, em Diadema, e Ci- dade de Deus, no Rio, revelando um quadro de brutalidade policial cujas raízes parecem ser mais profundas que o ato de indivíduos isolados.

Além disso, os recentes movimentos de reivindicação salarial envolvendo as polícias estaduais brasileiras adicionaram um ingrediente inédito à história das polícias brasileiras, e raro na história das polícias no mundo: uma greve. Em Minas Gerais, justamente uma das forças policiais mais respeitadas da Federação, o movimento teve componentes de violência que terminaram por propor dramaticamente uma velha questão de sociologia política: Quis custodiet ipsos/Custodes? ("Quem guardará os próprios guardas?").

A par da perplexidade diante do ineditismo do ocorrido, esses eventos descortinaram uma preocupante situação: existe uma grande ignorância no Brasil em relação ao sistema de Justiça Criminal em geral e às organizações policiais em particular. Este desconhecimento não decorre apenas do desprestígio do tema da Justiça Criminal nos meios acadêmicos, mas também de um certo insulamento das próprias organizações do sistema. Nem todas estão dispostas a ser estudadas e avaliadas por razões as mais diversas. No caso das polícias, justamente por serem a face mais visível do sistema de Justiça Criminal, freqüentemente estão presentes na mídia, seja atra- 
vés de forma mistificada, seja das sucessivas crises protagonizadas por elas devido às situações de brutalidade, violência e corrupção. A mistificação se dá pela falsa concepção de que o trabalho policial é dedicado exclusivamente ao combate ao crime, relegando a segundo plano o sem número de atividades rotineiras, assistenciais e de manutenção da ordem em que os policiais estão envolvidos (Bittner, 1990; Reiner, 1992). Da mesma forma, a visibilidade dos eventos relacionados a corrupção ou violência policial não esgotam as relações que a polícia mantém com o público, embora enfoquem um aspecto decisivo da atuação policial em sociedades democráticas.

Daí, talvez, uma razão do problema da segurança pública estar em pauta através dos eventos mais dramáticos de violações dos direitos humanos, o que de forma nenhuma esgota a discussão do tema da segurança pública. Da perspectiva do formulador de políticas públicas, o diagnóstico das relações inter-organizacionais entre polícia, Ministério Público, Judiciário e sistema prisional é igualmente crucial, da mesma maneira que problemas envolvendo a redundância das atividades das organizações policiais, dualidade de seus comandos, dispersão de recursos e estratégias de controle interno e externos (Paixão, 1993). De qualquer maneira, eventos dramáticos são oportunidades que costumam desencadear processos importantes de reforma, não obstante as raízes da propensão à violência policial estarem localizadas, muitas vezes, no cotidiano operacional das organizações (Skolnick e Fyfe, 1993).

Nossa ignorância a respeito do funcionamento das polícias estaduais, bem como das organizações do sistema de justiça criminal, e a forma mistificada do enfoque dado ao problema policial pode estar na origem de algumas prescrições freqüentemente propostas para reforma das polícias. A primeira delas consiste na idéia de que existe uma estrutura ideal de organização policial, e que a atual estrutura não se coaduna com este modelo. No Brasil, a definição da estrutura e função das polícias é matéria constitucional: cabe à Polícia Federal a apuração de infrações com repercussão interestadual e a repressão e prevenção ao tráfico de entorpecentes; à Polícia Civil as funções de polícia judiciária; e às polícias militares o de policiamento ostensivo (Constituição de 1988, Cap. III, art.144). ${ }^{6}$ Qual o modelo a ser perseguido, entretanto, é algo que não fica claro. Aparentemente, o pano de fundo dessa ordem de crítica repousa na idéia de que modelos descentralizados de comando e organização são condições necessárias para a transição a um modelo de polícia “orien- tado comunitariamente", em contraposição a um modelo "orientado profissionalmente" que parece ainda prevalecer na definição constitucional e como orientação doutrinária em muitas organizações policiais estaduais. ${ }^{7}$ Entretanto, nem o número de forças policiais autônomas existente, nem a centralização/descentralização de comandos e sua aproximação com a comunidade em que atuam parecem guardar qualquer relação com os objetivos das organizações policiais, com métodos de policiamento utilizados ou com sua relação com o público (Bayley, 1992).

Na realidade, o ponto de desconforto em relação à atual estrutura está na existência de uma força policial militar: uma Polícia Militar não se coaduna com a realidade democrática das sociedades modernas. Exposto dessa forma crua e sem qualificações, o argumento não tem respaldo empírico: a Itália ainda dispõe dos Carabinieri, a Espanha da Guardia Civil, a França da Gendarmerie, e a Holanda da Rijkspolitie. É verdade que o surgimento da polícia moderna se deu com a retirada dos exércitos no combate ao crime, dado que o combate à criminalidade exigia uma força repressiva mais especializada. Combater o crime não é o mesmo que ir à guerra. Contudo, isto não significou a emergência de forças civis de manutenção da ordem pública que, aliás, já existiam, e eram extremamente permeáveis ao mandonismo local. O que ocorreu foi uma engenharia institucional de construção de um modelo quase-militar de policiamento, ainda prevalecente em muitos países do mundo (Monkkonen, 1992; Lane, 1992), segundo o qual o controle social coercitivo passa a ser exercido por especialistas em conflitos e desvios da ordem industrial e urbana (Silver, 1967). O que poderia estar em jogo é a oposição entre modelos distintos de policiamento: o anglo-saxão, que seria uma polícia descentralizada, apartidária, não militar e que exerce a coerção por consenso; e o modelo francês, que seria uma polícia de Estado, centralizada, politizada, militarizada e com baixa aprovação pública. Permanece, entretanto, a evidência empírica de que esses modelos raramente são encontrados em estado puro (Horton, 1995; Lévi, 1997).

Da mesma forma como acredita-se numa estrutura ideal de organização da atividade policial, existe a crença de que elas são passíveis de formas ideais e descontextualizadas de controle dessas atividades. Nas fórmulas ideais de controle da polícia não há espaço para a existência de uma Justiça Militar. A questão do controle da ação policial é extremamente complexa, e é preocupação da sociedade em geral, como também das próprias organizações policiais. Do ponto de vista organizacional, en- 
volve desde mecanismos de seleção, recrutamento e formação até formas de controle disciplinares internos (que, no Brasil, alguns acreditam ser excessivamente rígidos) além de formas externas de controle como os tribunais. ${ }^{8}$

\section{ACCOUNTABILITY E POLÍCIA}

A discussão anterior é mais ampla e envolve o controle que a própria comunidade tem sobre a polícia. O termo accountability refere-se a esta adequação entre comportamento da polícia e objetivos da comunidade. Os mecanismos de controle podem variar das formas exclusivamente externas de controle das polícias, como os governantes e políticos, a mídia e movimentos de defesa de direitos humanos (Reiss, 1993; Sherman; 1997; Reiner, 1992) até mecanismos internos, como enquadramentos disciplinares, utilização de tecnologias de comunicação, treinamento e socialização em valores da corporação (Kenning, 1983; Manning, 1983).

$\mathrm{O}$ dilema brasileiro de alguns setores que discutem política de segurança no Brasil consiste em equacionar essas várias instâncias de controle sob o denominador do controle exclusivamente externo da polícia. Isto ocorre porque a atividade policial envolve uma dimensão moral que diz respeito à questão de se a polícia está ou não tratando os cidadãos de acordo com os princípios da cidadania. Embora formulada de modo direto e simples, o enfrentamento da questão requer reconhecimento de sua complexidade e ambigüidade, pois a permeabilidade da organização policial a demandas por soluções extralegais é fenômeno já observado no Brasil (Paixão e Beato, 1997) ou nos Estados Unidos (Skolnick e Fyfe, 1993).

Além disso, no caso brasileiro parece existir consenso quanto à eficácia de formas exclusivamente externas de controle sobre a polícia. Acredita-se que isso diminuirá a propensão da polícia à brutalidade. Contudo, é possível argumentar, e alguns autores o fazem, justamente o contrário, isto é, que a extinção de instâncias internas de controle não diminui a impunidade de crimes cometidos por policiais, mas podem aumentá-la (Bayley, 1985; Skolnick e Fyfe, 1993). Estamos claramente diante de questões empíricas: em que medida mecanismos de regulação interna da atividade policial podem ser mais bem informados do que mecanismos externos? Poderíamos avançar a hipótese de que mecanismos de regulação internos, por serem mais completos e extensivos, conseguiriam tratar de vários tipos de má conduta policial, e não apenas daquelas mais dramáticas e visíveis para a mídia e para a população. De qualquer forma, esses eventos críticos não devem obscurecer a natureza complexa da atividade policial e a função que cumprem as organizações policiais nas sociedades modernas.

A similaridade de problemas que a polícia enfrenta talvez seja o resultado de que, embora os contextos socioculturais sejam muito distintos, a função das polícias é essencialmente a mesma.

Em primeiro lugar, a função policial classicamente, distingue-se das atividades do exército por dirigir-se a dois aspectos centrais no sistema de segurança pública: o primeiro diz respeito às atividades de manutenção da ordem, e o segundo ao aspecto simbólico da justiça (Bayley, 1994; Bittner, 1990). A manutenção da ordem se dá mediante a presença visível do Estado e não se refere exclusivamente aos delitos criminais, que constituem menos de $15 \%$ do que é efetivamente realizado pelo policiamento ostensivo, mas às atividades de pacificação, mediação de conflitos, inclusive em âmbitos doméstico, patrulhamento e, em volume significativo, assistenciais ${ }^{9}$ (Banton, 1964; Muir, 1977; Fielding, 1984; Bittner, 1990). A presença simbólica da Justiça, por outro lado, refere-se à implementação da lei e à certeza de punição quando normas sociais são feridas. Trata-se de atividade que requer grande apego à legislação e aos procedimentos da legislação penal, ao passo que o policiamento ostensivo refere-se mais ao universo da "ordem social" difusamente e vagamente concebido pelas pessoas em seu dia-a-dia. ${ }^{10}$

No Brasil, por força de determinação constitucional, cabe às polícias militares a primeira tarefa, e às polícias civil e federal a segunda. Daí que algumas propostas sejam de unificar as polícias, como se fosse possível unificar funções cuja formação profissional e regras de ordem prática são bastante distintas. Em qualquer organização policial do mundo, havendo ou não comando unificado, essas funções são separadas e redundam em culturas intraorganizacionais distintas (em nosso caso, isto introduz um elemento de tensão inter-organizacional).

Em segundo lugar, diretamente relacionados a esta última questão, estão os aspectos jurisdicionais na atuação das polícias: quem faz o que dentre as várias polícias. Um dos pontos de conflito entre forças policiais decorre dos atritos e tensões a respeito de onde começam e terminam o policiamento ostensivo e a atividade investigatória. Com base nestes atritos jurisdicionais, muitas vezes empreendem-se ações divorciadas e com pouca articulação de informações e estratégias entre essas organizações (Paixão, 1993). Projetos bem-sucedidos de colaboração entre es- 
tes dois segmentos em outros países iniciaram-se justamente pela articulação entre estas duas atividades, dentre outras razões porque ela é mais eficaz no combate ao crime (Bayley, 1994).

O terceiro, aparentemente decisivo na explicação dos recentes movimentos entre os praças militares observado nos estados, diz respeito à cultura organizacional das polícias. Melhor seria dizer, às várias culturas organizacionais existentes nas polícias civis ou militares. De um lado, temos a estrutura hierárquica e disciplinada idealizada pela concepção de seus membros mais graduados. Os ranks superiores da organização tendem a uma perspectiva mais gerencial e administrativa delas. Como tal, acreditam que o organograma traduz o sistema de hierarquia e o fluxo de comando organizacional. De outro, porém, temos uma atividade profissional e altamente discricionária, que, para ser adequadamente realizada, exige um grande grau de autonomia e iniciativa (Ianni e Ianni, 1983). O policial na "linha de frente" não tem diretrizes genéricas de atuação ou arcabouço jurídico e formal a amparar muitas de suas decisões, simplesmente porque isto é impossível em muitos casos. O que se requer é uma boa dose de senso prático e a atuação sob a liderança de profissionais mais experientes, como ocorre em outras profissões, por exemplo, médicos, enfermeiros ou professores. Essa é uma das características mais marcantes da atividade policial em relação a organizações puramente militares, como o exército. Disciplina, hierarquia e obediência cega a normas regimentais são atributos deste último, e também de concepções idealizadas da organização policial.

Outra ordem de questões dirige-se às formas pelas quais o ambiente de uma organização pode influenciar sua estrutura organizacional (Reiss, 1993). Sabemos, pela literatura, que organizações policiais tendem a ser muito conservadoras em relação às suas estruturas tradicionais de operação, e qualquer tentativa de reordená-las não pode furtar-se ao confronto com esses elementos culturais das organizações policiais. $\mathrm{O}$ grau de centralização no comando dessas forças pode ter a ver com tradições estabelecidas no momento de criação da força policial pública. A observação da estrutura policial de outros países sugere que este componente de ordem genética é crucial (Bayley, 1985; Skolnick e Bayley, 1986). ${ }^{11}$

O Brasil possui ainda algumas características particulares em relação a suas forças policiais: embora o controle das polícias estaduais seja formalmente do exér- cito, do ponto de vista prático elas subordinam-se à autoridade do governador dos estados, o que sem dúvida nenhuma contribui para a diferenciação existente entre as forças estaduais. Outra característica é a multiplicidade de funções que cabe a elas desempenhar: tratam do policiamento ostensivo, das atividades de bombeiro, cuidam de florestas, de trânsito urbano e rodoviário e do policiamento de prisões, além de constituirem-se em forças auxiliares do exército, atuando efetivamente como guardas nacionais.

Por outro lado, em relação à polícia civil, tem-se discutido que tão grave quanto a militarização de uma força é a "advogadização" da segunda. A carreira de delegado de polícia, no Brasil, tem sido uma prerrogativa de advogados. Não é muito clara a razão da hegemonia da cultura jurídica na atividade policial investigatória. Mas, se atentarmos para a forma como a atividade de investigação policial é realizada e para sua localização no interior do sistema de justiça criminal brasileiro, estas razões ficam mais transparentes. O fluxo de processamento da justiça criminal inicia-se com uma ocorrência realizada pela Polícia Militar, que o comunica à Polícia Civil, que a resgistra. Registrada a ocorrência, a PC dá início ao inquérito policial, em que será averiguada a materialidade dos crimes, indicadas as testemunhas e tomados os depoimentos. Terminado o inquérito policial, ele é remetido ao Ministério Público que avaliará se está pronto ou não, para preparar a denúncia a ser remetida à Vara Criminal, onde tudo começa novamente. Conforme se pode ver, é extremamente complexo e muitas vezes moroso o fluxo da justiça criminal no Brasil. Isto dá origem a uma série de acusações entre as organizações que compõem o sistema, e talvez explique em parte por que a Justiça brasileira é tão tardia, freqüentemente incerta, e às vezes injusta, ao selecionar discriminatoriamente sua clientela. Na verdade, a polícia brasileira executa, através do inquérito policial, um ritual semelhante ao que é exercido pela Justiça através das varas criminais, com o delegado ocupando a posição de juiz de instrução. Talvez daí a suposta necessidade de um policial mais versado em direito do que em investigação policial.

Dado este enorme poder de que dispõe o policial, é ele, e não o juiz, quem julga se alguém ingressa ou não no sistema - que alguns identificam como a origem de alguns dos males endêmicos de nossas organizações policiais, como a corrupção e a tortura. Estes seriam decorrentes da deformação da atividade da polícia, que passa a exercer funções típicas da instrução criminal. 


\section{O CONTROLE DA CRIMINALIDADE EM OUTROS PAÍSES}

A discussão sobre o problema da polícia no Brasil é importante por destacar as imensas dificuldades que enfrentamos no que diz respeito a uma das organizações do sistema de Justiça Criminal. Nada foi dito a respeito da legislação penal, do código processual, do papel do Ministério Público, dos juízes ou das prisões, que são a ponta do sistema. Especialistas em cada um destes subsistemas certamente destacarão as enormes contradições, paradoxos e dilemas enfrentados.

De qualquer maneira, não obstante as prementes necessidades de nosso sistema de Justiça Criminal, é importante ressaltar que o controle da criminalidade não é relacionado exclusivamente a ele. Vários programas bem-sucedidos de controle da criminalidade podem estar fora do controle das organizações que compõem o sistema. Recentemente, o general Alberto Cardoso, que vem se destacando como um dos principais conselheiros do governo federal para assuntos de segurança pública, analisou a situação do tráfico de drogas no Rio, qualificando-o como um "problema de segurança nacional". O crime organizado estaria ameaçando a soberania nacional, criando verdadeiros estados paralelos em importantes estados da federação. Descreveu uma realidade que muitos pesquisadores sobre o tema repetem há muitos anos, e que moradores de localidades dominadas pelo tráfico conhecem muito bem: os traficantes, aproveitando-se do vácuo de poder público em determinadas áreas do território nacional, criaram núcleos paralelos de poder, imiscuindo-se até mesmo nas formas tradicionais de exercício de poder.

A polêmica ficou por conta do atual governador do Rio de Janeiro, que sustentou que ali não se produzem armas, tampouco drogas. Dentro dos limites de atuação de seu secretário de Segurança, tudo estaria sendo feito: as apreensões de armas e drogas cresceram significativamente durante sua gestão. Logo, o problema é do governo federal que não dá conta de suas tarefas. E assim, entre trocas de acusações e balas perdidas, o tráfico de drogas carioca continua a florescer esplendorosamente.

Aparentemente, ambos parecem acreditar na eficácia de uma solução exclusivamente policial para o problema do tráfico de drogas. Este é o cerne da Deterrence Theory em criminologia. A teoria da dissuasão credita às organizações do sistema de Justiça Criminal a maior parcela no controle da criminalidade: se tivermos uma polícia preparada e eficiente, uma legislação adequada e um complexo de prisões com vagas suficientes para receber os delinqüentes, provavelmente as taxas de criminalidade cairão. Este quadro ideal parece uma utopia no caso brasileiro, onde a ação da polícia e do Judiciário parece não afetar o comportamento das taxas de criminalidade, como indicam algumas observações empíricas (Coelho, 1988): em São Paulo, entre 1981 e 1984 a polícia deixou de investigar $89 \%$ das ocorrências de roubo, $81 \%$ de estupro e $29 \%$ de homicídio (em contraste com a média americana de 12\%). Os tribunais liberaram, entre 1976 e 1984, 54\% dos denunciados por homicídio, $74 \%$ por estupro e $47 \%$ por roubo. Dos condenados saídos da prisão em 1982, apenas $12 \%$ haviam cumprido suas penas e $55 \%$ foram beneficiados por sursis (Coelho, 1988). Mesmo nos Estados Unidos, o efeito dissuasório da polícia e da Justiça tem sido posto em questão. Entre 1975 e 1989, a população prisional e a média do tempo das penas triplicaram sem que isto tenha representado um decréscimo significativo nas taxas de crime violento (Reiss et alii, 1993). De cada 1.000 arrombamentos detectados pelo Survey de vitimização, 390 casos são reportados à polícia, que consegue prender 40 pessoas, das quais serão condenadas 13 e apenas dez efetivamente cumprirão pena. Além disso, o tempo médio decorrido entre o delito e a prisão é de cinco meses. No Brasil, em 1988, calculava-se que, apenas para o julgamento dos processos existentes em Nova Iguaçu, a demora seria de 25 anos!

Do ponto de vista da atuação policial, o quadro é igualmente desalentador. Não existem evidências de que quanto maior o número de policiais, menor o número de crimes. Tais fundamentos para esta afirmação provêm de dois tipos de estudos: o que ocorre durante a greve de policiais e; correlações entre número de policiais e taxas de crimes. Um estudo sobre as greves ocorridas em Helsinque em 1944, e sobre a ocupação de Copenhagen pelos nazistas, quando houve também uma drástica redução do número de policiais, mostra que há um incremento em crimes contra a propriedade (roubo e furto), o que não deixa de ser uma demonstração da importância da polícia. Entretanto, estes estudos não foram controlados por outras localidades. No caso de Belo Horizonte, onde recentemente houve uma rápida greve, quase nenhuma alteração foi registrada nas taxas nesse período. Um segundo estudo, menos conclusivo ainda, abrangendo 56 cidades com mais de 250 mil habitantes em 49 estados americanos mostrou que a variância explicada nas taxas de criminalidade em relação ao número de policiais era muito pequena.

O Canadá, por exemplo, tem uma taxa de um policial para 353 habitantes e um número reduzido de 5,9 homi- 
cídios por 100 mil habitantes. Já a China tem um policial para 1.382 habitantes, e no entanto registra um número muito menor de homicídios (dois por 100 mil habitantes). No próprio Estado de Minas Gerais, existem regiões, como o Norte, com um número muito reduzido de policiais militares por habitantes (um policial por 1.500 habitantes), mas com baixas taxas de crimes violentos $(12,8$ por 100 mil habitantes), e outras como a Região Metropolitana de Belo Horizonte, com um padrão mais elevado de policiais (um policial por 700 habitantes) e um número igualmente elevado de crimes violentos (24 por $100 \mathrm{mil}$ ). Os Estados Unidos têm uma das mais altas taxas de população prisional (em 1990, para cada 100 mil habitantes, 426 estavam atrás das grades), o que equivale a quase dez vezes o número dos países nórdicos. Mas também uma das mais altas taxas de criminalidade violenta. Mais policiais e aumento da população prisional não diminuem o número de crimes, embora tenham um efeito importante na diminuição da taxa de medo da população - o que já é muito importante.

A introdução de penas mais severas pode, paradoxalmente, torná-las menos freqüentemente aplicáveis. Estados americanos que adotaram severas sanções para o porte de armas verificam que, após algum tempo, os policiais tendiam a aplicá-las em número muito menor. Estudos sobre a pena de morte não identificaram nenhum efeito sobre as taxas de criminalidade (Walker, 1985). A questão é que a dissuasão relaciona-se não ao grau de repressão, mas a um incremento nos custos do crime, além de um incentivo benéfico para o não-crime. Parte dessa atuação exigiria uma atuação mais proativa da polícia: crimes violentos não são fenômenos aleatoriamente distribuídos, mas geograficamente concentrados, o que pode ajudar a polícia a antecipar-se aos criminosos, ao invés de apenas reagir. A Justiça brasileira, por sua vez, encontra-se sobrecarregada de processos envolvendo pequenos delitos que terminam por emperrar sua atuação.

Mas, o que fazer diante de tais limitações? Existe um influente estudo realizado recentemente nos Estados Unidos pela Rand Corporation que nos conduz a uma perspectiva heterodoxa em relação ao problema (Rydell e Everingham, 1995). Atualmente, nos EUA, o problema do consumo de cocaína atinge cerca de sete milhões de americanos. Em meados da década de 80 , os números envolviam nove milhões de pessoas. O declínio no número de consumidores parece sugerir a eficácia dos programas adotados pelo governo de controle da oferta de drogas. Basicamente, estes programas consistiram em: controle em países produtores, através da erradicação de plantações e destruição de laboratórios de refino da pasta de coca; interdição através do confisco de drogas e propriedades nas fronteiras pela guarda costeira, Serviço de Imigração e Exército; e repressão doméstica, através da apreensão e confisco de drogas e propriedades por agentes federais, estaduais e locais. Juntos, estes programas utilizam $93 \%$ do orçamento destinado ao controle da cocaína, sendo a repressão doméstica a que consome mais recursos (73\%). Os 7\% restantes destinam-se a programas de controle através do consumo, especialmente no tratamento de viciados. O montante de recursos destinados a todos os quatro programas nos EUA é de 13 bilhões de dólares por ano.

Uma análise mais fina desses números, entretanto, mostra outras facetas interessantes do problema. O declínio observado no número de pessoas que utilizavam cocaína deu-se principalmente entre os usuários leves, isto é, aqueles que consumiam menos de uma grama por semana. Isto porque programas de controle da oferta de drogas através da repressão têm efeito principalmente sobre o preço da cocaína, o que termina afastando apenas os usuários "leves". Usuários "pesados" sempre estarão dispostos a consumir, sejam quais forem os riscos envolvidos ou o preço da droga. Para usuários pesados, os melhores resultados são obtidos através do tratamento, não porque isto vá curá-los. Quem lida com o problema sabe que o índice de reincidência é muito alto. Apenas 13\% dos viciados, segundo algumas estimativas, abandonam o vício por um largo período de tempo. Ocorre que, durante o período de tratamento, este tipo de usuário não está consumindo.

Se analisada a relação custo-benefício de cada um desses programas, as diferenças são impressionantes, conforme vemos na Tabela 1.

Para diminuir em $1 \%$ o consumo anual de cocaína nos EUA são necessários 783 milhões de dólares gastos em controle nos países produtores, 366 milhões na interdição em fronteiras, 246 milhões em repressão doméstica e 34 milhões em tratamento! São números bastante eloqüentes e que convidam à reflexão.

A novidade em estudos deste tipo está em não tratar o problema das drogas do ângulo exclusivo do tráfico, mas do consumo também. Ambos sustentam-se mutuamente. Já é tempo de deixarmos de lado formulações de programas de controle da criminalidade assentadas em oposições falsas, como repressão versus assistencialismo social. Ao lado de uma estratégia repressiva mais eficiente, pode-se pensar em solapar o tráfico também na base de recrutamento de delin- 
TABELA 1

Custo para Diminuir o Consumo de Cocaína em 1\% Estados Unidos - 1995

\begin{tabular}{lc} 
& Em US\$ milhões \\
\hline Formas de Diminuir o Consumo & Custo \\
\hline Controle em Países Produtores & 783 \\
Interdição em Fronteiras & 366 \\
Repressão Doméstica & 246 \\
Tratamento de Viciados & 34 \\
\hline
\end{tabular}

Fonte: Rydell e Everingham (1995).

qüentes, realizado amplamente entre as camadas mais desfavorecidas. Esta estratégia composta de controle, aliás, é familiar aos traficantes de favelas cariocas. Sua inserção nas comunidades se dá não através do uso exclusivo da força, mas da legitimação através do assistencialismo comunitário. O tratamento dos viciados, conforme foi discutido anteriormente, pode ser uma forma eficaz. Muitas vezes, a eficácia dos resultados está justamente em combinarem-se programas distintos de controle da droga, tanto na oferta como do consumo.

A mesma tendência é detectada em outro estudo realizado pela Rand Corporation, quando se analisou o impacto de diferentes estratégias para prevenção de crimes através de programas de intervenção comparadas à introdução de uma legislação dura. Os programas de intervenção incluíam:

- visitas a lares por assistentes sociais logo após o nascimento das crianças até os seis anos de vida;

- treinamento e terapia para famílias com crianças que demonstrassem comportamento agressivo na escola, ou estavam em vias de ser expulsas dela;
- quatro anos de incentivo monetário para induzir garotos carentes a se graduarem;

- monitoramento e supervisão de jovens secundaristas que tivessem demonstrado comportamento delinqüente.

O impacto destes programas é comparável ao da lei dos Three Strikes ${ }^{12}$ sobre as taxas de crime na Califórnia. Os resultados da relação custo/benefício de cada uma destas estratégias são exibidos na Tabela 2.

Constata-se que a estratégia de maior impacto é a legislação dura adotada na Califórnia, que foi capaz de reduzir o crime em $21,4 \%$. Em contrapartida, seu custo é extremamente alto, pois envolve a construção de prisões e a manutenção de pessoal especializado. Para reduzir em $1 \%$ o número de crimes graves, gasta-se 258 milhões de dólares e previne-se cerca de 61 crimes graves. Dois outros programas apresentam uma melhor relação custo/benefício: os de treinamento de pais e de incentivo à graduação. Embora tenham um impacto menor na redução das taxas $(6,6 \%$ e $15,5 \%$, respectivamente), são muito mais baratos. O custo para reduzir em $1 \%$ o total de crimes é da ordem de 55 milhões de dólares para o treinamento de pais e 37 milhões para o incentivo a graduação. Se analisado o número de crimes prevenidos por cada milhão de dólares, as diferenças são ainda mais favoráveis aos programas de intervenção social: o treinamento previne 158 crimes e o incentivo 258 crimes por milhão de dólares. Não se trata de optar por programas sociais versus programas repressivos, mas simplesmente ressaltar a possibilidade de se fazer uma combinação ótima de estratégias de intervenção entre crianças e adolescentes. A legislação tem um bom impacto na redução de taxas de crimes $(21,4 \%)$ ao custo de 5.520 bilhões de dólares. Com um pequeno acréscimo de 568 milhões de dólares, podese obter uma redução de $36,9 \%$ nas taxas.

TABELA 2

Programas de Intervenção na Infância e Adolescência

Estados Unidos - 1996

\begin{tabular}{|c|c|c|c|c|c|}
\hline \multirow[b]{2}{*}{ Indicadores } & \multicolumn{5}{|c|}{ Programas de Intervenção na Infância e Adolescência } \\
\hline & $\begin{array}{l}\text { Three } \\
\text { Strikes }\end{array}$ & $\begin{array}{l}\text { Visitas } \\
\text { a Lares }\end{array}$ & $\begin{array}{c}\text { Treinamento } \\
\text { de Pais }\end{array}$ & $\begin{array}{l}\text { Incentivos à } \\
\text { Graduação }\end{array}$ & $\begin{array}{l}\text { Supervisão de } \\
\text { Delinqüentes }\end{array}$ \\
\hline Crimes Prevenidos (\%) & 21,4 & 5,5 & 6,6 & 15,5 & 1,8 \\
\hline Custo Anual do Programa (US\$ milhões) & 5.520 & 3.155 & 361 & 568 & 241 \\
\hline Custo para Redução em 1\% do Crime (US\$ milhões) & 258 & 573 & 55 & 37 & 131 \\
\hline Número de Crimes Prevenidos (para cada milhão de dólares) & 61 & 11 & 157 & 258 & 72 \\
\hline
\end{tabular}

Fonte: Greenwood et alii, 1996. 
A Holanda oferece outro exemplo de uma política de segurança bem-sucedida, que se utiliza de abordagens não convencionais sobre o crime, incluindo uma reformulação de natureza conceitual (Dijk, 1997). Até meados dos anos 60, a sociedade holandesa era relativamente bem integrada e com baixas taxas de criminalidade. A partir daí, e com razões que têm a ver com o aumento da riqueza e com processos de modernização e urbanização, assiste-se a um incremento das taxas de crimes contra a propriedade. O governo holandês apresenta uma política de controle da criminalidade com três objetivos práticos: prevenção do crime através de projetos ambientais; fortalecimento da vigilância em zonas de alto risco; e melhor integração dos jovens através da escola e de um programa de integração ao mercado de trabalho. Foram destinados 30 milhões de dólares para o programa neste primeiro ano, sendo $10 \%$ destinados à sua avaliação. A base cognitiva desta política era a "prevenção situacional do crime" (Clarke, 1997). A idéia não é reformar indivíduos, o que é extremamente difícil, mas dificultar as condições de ocorrência de crimes. Isto é feito mediante a contratação de desempregados para atuar como guardas civis uniformizados, mas sem autoridade policial. Além disso, existe uma Plataforma Nacional de Controle do Crime que analisa tendências da criminalidade a cada ano e define prioridades e estratégias de ação para cada tipo de crime. Em relação ao roubo à mão armada, por exemplo, conseguiu-se uma significativa redução, tornando os alvos deste tipo de ação mais difíceis. Os comerciantes foram orientados a deixar pouco dinheiro em caixa, a utilizar alarmes e outros obstáculos à ação criminosa, ou a instalar câmaras de vídeo e coisas assim. O que distingue a "prevenção situacional do crime" é que ela busca articular esforços da sociedade e do governo no sentido de controlar a incidência de tipos específicos de crime através da manipulação de fatores tais como a disponibilidade de alvos, o incremento da vigilância e a motivação dos agressores (Felson, 1994). Trata-se de política que não abdica da necessidade de termos um sistema de Justiça Criminal eficiente e justo, mas que reconhece as limitações dele no controle da criminalidade.

Infelizmente, ainda não dispomos de análises mais conseqüentes a amparar a formulação de programas de controle da criminalidade. Nossas autoridades ainda acreditam que bom senso, boas intenções e intuição sejam suficientes para a formulação de políticas de segurança. A dura realidade de nossos dias parece contrariar cada vez mais esta percepção.

\section{POLÍTICAS PÚBLICAS DE SEGURANÇA NO BRASIL}

Parece que uma das razões do fracasso e da inexistência de políticas nessa área reside num plano puramente cognitivo. A proposição de políticas públicas de segurança, no Brasil, consiste num movimento pendular, oscilando entre a reforma social e a dissuasão individual. A idéia da reforma decorre da crença de que o crime resulta de fatores socioeconômicos que bloqueiam o acesso a meios legítimos de se ganhar a vida. Esta deterioração das condições de vida traduz-se no acesso restrito de alguns setores da população a oportunidades no mercado de trabalho e de bens e serviços, assim como na má socialização a que são submetidos nos âmbitos familiar, escolar e na convivência com subgrupos desviantes. Conseqüentemente, propostas de controle da criminalidade passam inevitavelmente tanto por reformas sociais de profundidade como por reformas individuais voltadas a reeducar e ressocializar criminosos para o convívio em sociedade. A par das políticas convencionais de geração de empregos e combate à fome e à miséria, ações de cunho assistencialista visariam minimizar os efeitos mais imediatos da carência, além de incutir em jovens candidatos potenciais ao crime novos valores através da educação, da prática de esportes, do ensino profissionalizante e do aprendizado de artes e na convivência pacífica e harmoniosa com seus semelhantes. Quando isto já não é mais possível, que se reformem então aqueles indivíduos que caíram no mundo do crime através do trabalho e da reeducação nas prisões.

De outro lado, é igualmente forte a crença de que a criminalidade encontra condições ideais de florescimento quando é baixa a disciplina individual e o respeito a normas sociais. Conseqüentemente, políticas de segurança pública enfatizam a necessidade de uma atuação mais decisiva do Poder Judiciário e das instâncias de controle social. Isto significa legislações mais duras e maior policiamento ostensivo, de forma tal que as punições dos delitos sejam rápidas, certas e severas. Se necessário, até mesmo a atuação das Forças Armadas é requisitada, merecendo o aplauso da população. Não se descarta, ainda, o efeito dissuasório que soluções finais, como a pena de morte, teriam sobre o comportamento criminoso. $\mathrm{O}$ argumento é que não se trata de vingança, mas exemplo para que homens de bem não caiam em tentação.

Discursos inflamados dão suporte a ambas as versões, cujo grau de combustão é tanto maior quanto mais afer- 
rados a questões de princípio ideológico. Do ponto de vista da modificação de valores das pessoas, reconhece-se hoje como isso é extremamente difícil mediante políticas públicas. Os educadores de rua e profissionais que lidam com menores infratores sabem muito bem como é árdua essa tarefa com meninos de rua. E isto porque se acena com soluções de médio e longo prazos para garotos (às vezes nem tão garotos assim) que obtêm satisfações imediatas de sua atividade nas ruas. Além disso, sabe-se que nem todos os meninos de rua ou jovens desempregados são candidatos naturais a uma carreira criminosa. Estudos que acompanharam jovens de uma cidade americana ao longo de suas vidas mostram que, se um número significativo deles teve problemas com a polícia alguma vez em suas vidas, o número dos que reincidiram outras vezes é muito menor - menos de 6\%. O mais curioso, entretanto, é que este pequeno número de criminosos era responsável por mais de $50 \%$ das queixas criminais. Isto significa que apenas uma parcela muito pequena desses jovens seguiu uma carreira criminosa (Wolfang et alii, 1972).

No outro extremo do movimento pendular estão aqueles que acreditam que o problema do crime é fundamentalmente uma questão de polícia e de legislação mais repressivas. A dissuasão do comportamento criminoso, então, passaria necessariamente por uma atuação mais intensiva do sistema de Justiça Criminal, conforme discutimos anteriormente.

Mais recentemente, a orientação oficial do governo federal tem se calcado na sociologia crítica (Taylor e Young, 1980), cuja concepção de crime baseia-se nos direitos humanos (Ministério da Justiça, 1996). Isto abriu a possibilidade de incluir, dentre as modalidade de crime, aqueles cometidos pelo Estado. Daí a importância de se controlarem as organizações componentes do aparato repressivo que parece ter sido a tônica da atual política de segurança em âmbito federal.

Um exame mais atento, entretanto, mostra que tais modelos e teorias não são necessariamente excludentes, mas complementares. Um modelo de segurança que se preocupe com a contenção e controle do Estado em relação ao direito dos cidadãos não pode furtar-se à constatação de que segurança é igualmente um direito humano aliás, consagrado na Declaração Universal dos Direitos do Homem. Por outro lado, o sistema de Justiça Criminal em geral e a atuação policial em particular serão tanto mais eficientes no exercício de suas funções de dissuasão quanto mais amparados pelas pessoas e comunidades nas quais atuam.
O que tem sido eficaz são programas e estratégias de segurança baseados numa articulação multiinstitucional entre Estado e sociedade (Sherman, 1997; Short, 1997; Greenwood et alii, 1996; Felson e Clarke, 1997). O crime é uma coisa muito séria para ser deixada apenas nas mãos de policiais, advogados ou juízes, pois envolve dimensões que exigem a combinação de várias instâncias sob o encargo do Estado e, sobretudo, a mobilização de forças importantes na sociedade. O Estado deve mobilizar organizações que atuam nas áreas da saúde, educação, assistência social, planejamento urbano e, naturalmente, da segurança.

Muitos poderiam argumentar que o que se propõe é, na verdade, quase um modelo do "bom governo". Um Estado que conseguisse simultaneamente responder às demandas sociais nesses diversos setores estaria respondendo às atribuições que lhe cabem minimamente. Isto é verdade. A diferença está em que a alocação desses recursos se daria não em torno de prioridades governamentais (educação, saúde, ou segurança), mas da identificação de locais e grupos no interior da sociedade que mereceriam um tratamento prioritário.

Por outro lado, isto não significa que o Estado devesse paralisar suas atividades nessas áreas em favor do atendimento de populações e áreas assoladas pela criminalidade violenta, mas simplesmente reconhecer que o atendimento nessas áreas é realmente prioritário. $\mathrm{O}$ fenômeno da criminalidade urbana violenta não é distribuído aleatoriamente pela área urbana, mas está localizado em alguns poucos grupos e locais (Sherman, 1997). Daí não haver combate efetivo ao crime que não leve em conta a recuperação das áreas degradadas pela violência nos grandes centros urbanos.

Em que nível de governo devem ser prioritariamente tratadas as questões acerca de segurança pública? As respostas devem ser relativizadas. A maioria dos problemas são locais e devem ser definidos e tratados localmente. Outras coisas são de competência do governo federal. Além das atribuições definidas constitucionalmente, são centrais na formulação e implementação dessas políticas, tais como as de construção e manutenção de um sistema de indicadores sociais de criminalidade, ou o estímulo a pesquisas sobre determinados "problemas" que preocupam o governo federal. Isto seria feito através da indução à pesquisa sobre estes problemas identificados pelo governo federal. Atenção especial deveria ser dada não apenas ao estímulo às pesquisas, cuidando para que elas também tenham recomendações práticas, com especial atenção aos mecanismos de avaliação de implementação das políticas sugeridas. 
Em bases estritamente cognitivas, a formulação de políticas públicas de segurança pode perfeitamente prescindir de quaisquer abordagens culturalistas para a formulação de programas e projetos. Não é necessário, para se controlar a criminalidade, reformar a personalidade das pessoas. Não acreditamos que a mudança de valores das pessoas deva ser objeto de políticas governamentais. $\mathrm{O}$ que deve ser oferecido às pessoas são orientações acerca das conseqüências de suas ações, tanto em direção ao crime como em relação ao não-crime (Wilson, 1983; Clarke, 1997; Clarke e Cornish, 1985).

\section{NOTAS}

E-mail do autor: beato@ dedalus.lcc.ufmg.br

Versão anterior deste artigo foi apresentada nos seminários sobre reforma do Estado, promovidos pela Fundação Joaquim Nabuco em agosto de 1998, em Recife, bem como no seminário "A polícia e o controle civil", promovido pelo Núcleo de Estudo de Violência da USP. Agradeço aos comentários feitos pelos debatedores e pelas platéias presentes nessas ocasiões. Como de praxe, a responsabilidade pelo texto final é inteiramente minha. Este trabalho não teria sido possível sem o apoio do CNPq.

1. Outros indicadores de custo da criminalidade violenta agregariam dados sobre como a população de uma localidade responde ao problema do crime através de movimentos migratórios ou às perdas que o crime acarreta para o turismo (Glaeser et alii, 1998).

2. Esta despesa inclui os gastos com a Polícia Militar (417 milhões); o Tribunal de Justiça (245 milhões) e a Secretaria de Segurança (136 milhões). O restante é dividido com o Tribunal de Justiça Militar, o Tribunal de Alçada, o Ministério Público e a Secretaria de Justiça.

3. Coelho (1988) refere-se a isto como o argumento da justiça distributiva, cujos equívocos são discutidos por ele a partir do argumento da dissuasão.

4. Não é isto que as evidências mostram. Muitas vezes, o desenvolvimento e a riqueza podem estar associados a taxas mais altas de criminalidade (Beato Filho, 1998; Cohen e Felson, 1979).

5. Esta estratégia, conhecida como problem-solving, tem sido adotada com grande sucesso pelos responsáveis pelo controle da criminalidade em outros países. Ver, a respeito, Sherman (1997) e Bayley (1994).

6. Esta definição constitucional da estrutura das polícias é ressaltada por alguns autores como um dos problemas que dificultam processos de reforma das polícias, pois impõem a todos os estados da Federação o mesmo modelo estrutural de polícia (Coelho, 1988; Paixão, 1993).

7. Daí, talvez, a razão de o policiamento comunitário ser tão fortemente recomendado na Conferência Nacional sobre Segurança, Justiça e Cidadania, promovido pelo Ministério da Justiça, Movimento Viva Rio e PNUD, em maio de 1997.

8. Para uma discussão da influência de controle internos e externos sobre a polícia, ver Punch (1983). Ver também o capítulo 7 de Bayley, 1985.

9. O conhecimento deste universo de práticas e procedimentos de ordem prática é condição para implementação de políticas de inovação bem-sucedidas. Ver Reiner (1992, cap.7) e Bayley (1994).

10. Sobre o impacto que esta concepção de ordem social de senso comum tem sobre o policiamento, ver Wilson (1984), especialmente o capítulo 5: "Broken windows: the police and neghborhood safety".

11. Mesmo em países ocupados após a Segunda Guerra, no qual foram impostas modificações de âmbito jurisdicional e organizacional de suas polícias, assistiuse logo após a retirada das tropas de ocupação a emergência de suas estruturas tradicionais. Na Alemanha, recriou-se o sistema de polícia existente no Segundo Reich (1872-1918) e na República de Weimar (1919-1933), segundo o qual a responsabilidade pela polícia eram dos estados (Länder) e de algumas poucas grandes cidades. Os japoneses rejeitaram o sistema descentralizado imposto atra- vés de sucessivas votações nas comunidades, embora não tenham retornado integralmente ao sistema anterior (ver Bayley, 1985).

12. A legislação dos Three Strikes é extremamente severa. Ela estabelece que após a terceira reincidência o delinqüente terá uma pena de 25 anos, não importando a gravidade do delito cometido.

\section{REFERÊNCIAS BIBLIOGRÁFICAS}

BANTON, M. The policeman in the community. London, Tavistock, 1964.

BAYLEY, D.H. Patterns of policing: a comparative international analysis. N. J., Rutgers University Press. New Brunswick, 1985.

"Comparative organization of the police in english-speaking countries". In: TONRY, M. e MORRIS, N. (eds.). Modern policing. Crime and Justice. Chicago/London, The University of Chicago Press, v.15, 1992, p.509-546. 1994

BEATO FILHO, C.C. "Determinantes da criminalidade em Minas Gerais". Revista Brasileira de Ciências Sociais, v.13, n.37, 1998, p.74-89.

BITTNER, E. Aspects of police work. Boston, Northeastern University Press, 1990.

BRANT, V.C. O trabalhador preso no Estado de São Paulo. São Paulo, Cebrap, 1986.

CALDEIRA, C. Apresentação. Arché, 1998.

CLARKE, R.V. (ed.). Situational crime prevention: sucessful case studies. Guiderland/New York, Harrow and Heston Publishers, 1997.

CLARKE, R.V. e CORNISH, D.B. "Modeling offenders decisions: a framework for research and policy". In: TONRY, M. e MORRIS, N. (eds.). Crime and justice. An annual review of research (v.6). Chicago, Chicago University Press, 1985.

COELHO, E.C. "A administração do sistema de Justiça Criminal". Dados. Rio de Janeiro, n.29, v.1, 1986, p.61-81.

. "A criminalidade urbana violenta”. Dados. Rio de Janeiro, v.31, n. 2,1988, p. $145-183$

COHEN, L. e FELSON, M. "Social change and crime rate trends: a routine approach. American Sociological Review, 44, 1979, p.588-608.

DIJK, J.J.M. van. In: FELSON, M. e CLARKE, R.V. (eds.). Business in crime prevention. Criminal Justice Press. New York, Monsey, 1997.

DUNN, W.N. Public policy analysis. Prentice-Hall, Inc., Englewood Cliffs, 1981.

FELSON, M. Crime and everyday life. Pine Forge Press. Thousand Oaks/London/ New Delhi, 1994.

FELSON, M. e CLARKE, R.V. Business in crime prevention. Monsey/New York, Criminal Justice Press, 1997.

FIELDING, N. "Police socialisation and police competence". British journal of sociology, v.35, n.4, 1984.

GLAESER, E.; LEVITT, S. e SCHEINKMAN, J. The economics effects of crime: an overview, 1998, mimeo.

GONÇALVES, J.A. Os custos do crime e da contravenção, 1996, mimeo.

GREENWOOD, P.W.; MODEL, K.E. e RYDELL, P. Diverting children from a life of crime: measuring costs and benefits. Rand Corporation, 1996.

GUSFIELD, J.R. The culture of public problems: drinking-driving and the simbolic order. Chicago/London, The University of Chicago Press, 1981.

HORTON, C. Policing policy in France. London, Policy Studies Institute, 1995.

IANNI, E.R. e IANNI, F.A.J. "Street Cps and management Cops: the two cultures of policing. In: $\mathrm{PUNCH}, \mathrm{M}$. (org.). Control in the police organization. Cambridge/Massachusetts, London/England, The MIT Press, 1983, p.251-276.

KELLING, G.L. "On the accomplishments of de police". In: PUNCH, M. (org.). Control in the police organization. London/England, The MIT Press. Cambridge/Massachusetts, 1983, p.152-168.

LANE, R. "Urban police and crime in nineteenth-century America". In: TONRY, M. e MORRIS, N. (eds.). Modern policing. Crime and justice. Chicago/ London, The University of Chicago Press, v.15, 1992, p.1-50. 
LÉVI, R. "A crise do sistema policial francês hoje". Tempo social. São Paulo, v.9, n.1, p.53-77, maio 1997.

MANNING, P.K. "Organizational constraints and semiotics. In: PUNCH, M. (org.). Control in the police organization. London/England, The MIT Press. Cambrige/Massachussets, 1983, p.169-193.

MINISTÉRIO DA JUSTIÇA. Programa Nacional de Direitos Humanos. Brasília, 1996.

MONKKONEN, E.H. "History of urban police". In: TONRY, M. e MORRIS, N. (eds.). Modern policing. Crime and Justice. Chicago/London, The University of Chicago Press, v.15. p.547-580, 1992.

MUIR, Jr., K.W. Police: streetcorner politicians. Chicago, Chicago University Press, 1977.

PAIXÃO, A.L. A política da polícia. Estudos Implementares FJP, 1993, mimeo.

PAIXÃO, A.L. e BEATO FILHO, C.C. "Crimes, vítimas e policiais". Tempo social. São Paulo, v.9, n.1, maio 1997, p.233-248.

PIQUET CARNEIROS, L.; PHEBO, L.; COUTOLENC, B.; CANO, I. e PINTO, M. Magnitude e custos econômicos da violência no Rio de Janeiro, 1998, mimeo.

PUNCH, M. (org.). Control in the police organization. Cambridge/Massachusetts, London/England, The MIT Press, 1983.

REINER, R. The politics of the police. Toronto/Buffalo, University of Toronto Press, 1992.

REISS Jr., A.J. e ROTH, J.A. (eds.). Understanding and preventing violence. Panel on the understanding and control of violent behavior. Committee on Law and Justice. Comission on Behavioral and Social Sciences and Education, National Research Council. Washington DC, National Academy Press, 1993.
RYDELL, P.C. e EVERINGHAM, S.S. Controlling cocaine: spply versus demand programs. Drug Policy Research Center, Rand Corporation, 1995.

TAYLOR, W. e YOUNG, J. Criminologia crítica. Rio de Janeiro, Ed. Graal, 1980.

SHERMAN, L. "Thinking about crime prevention". In: SHERMAN, L.; GOTTFREDSON, D.; MACKENZIE, D.; ECK, J.; REUTER, P. e BUSHWAY, S. Preventing crime: what works, what doesn't: what's promising. National Institute of Justice, 1997.

SKOLNICK, J.H. e BAYLEY, D.H. The new blue line: police innovation in six american cities. London/New York, The Free Press, 1986.

SKOLNICK, J.H. e FYFE, J.J. Above the law: police and the excessive use of force. N.York/Toronto/Oxford/Singapore/Sydney, The Free Press, a Division of Mcmillan Inc., 1993

SHORT Jr., J.F. Poverty, ethnicity and violent crime. Westview Press, 1997.

SILVER, A. "The demand for order in civil society: A review of some themes in the history of urban crime, police, and riot". In: BORDUA, D.J. The police: six sociological essays. New York/London/Sydney, John Wiley \& Sons, 1967, p.1-25.

VAN DIJK, J.J.M. In: FELSON, M. e CLARKE, R.V. (ed.). Business in crime prevention. Monsey/New York, Criminal Justice Press, 1997.

WALKER, S. Sense and nonsense about crime: a policy guide. Monterey, California Brooks/Cole Publishing Company, 1985.

WILSON, J.Q. Thinking about crime. New York, Vintage Books, 1983.

WILSON, J.Q. e HERRENSTEIN, R.J. Crime and human nature: the definitive study of the causes of crime. New York, Touchstone Book. Simon \& Schuster, Inc., 1985.

WOLFGANG, M.E.; FIGLIO, R.M. e SELLIN, T. Delinquency in a birth cohort. Chicago, University of Chicago Press, 1972 